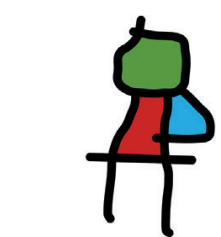

SEICAIP

\section{Allergologia et immunopathologia}

Sociedad Española de Inmunología Clínica, Alergología y Asma Pediátrica

www.all-imm.com

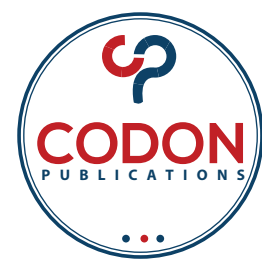

\title{
Local allergic rhinitis in children: A systematic review
}

\section{Fausto Yoshio Matsumoto*, Tessa Rachel Tranquillini Gonçalves, Dirceu Solé, Gustavo Falbo Wandalsen}

Department of Pediatrics, Universidade Federal de São Paulo, São Paulo, Brazil

Received 12 December 2021; Accepted 29 December 2021

Available online 1 March 2022

\section{KEYWORDS \\ adolescent; \\ child; \\ phenotype; \\ prevalence; \\ rhinitis}

\begin{abstract}
Background: Local allergic rhinitis (LAR) is a well-defined and reported phenotype in adults, but data is scarce for children and adolescents, and it is probably an undiagnosed and highly underestimated condition in childhood.

Objectives: The objectives of this systematic review were to identify original observational studies published on LAR in children and adolescents and to describe the prevalence and characteristics of this phenotype in the pediatric age group.

Methods: A systematic search was performed in PubMed and EMBASE databases. The search was limited to publications on humans, written in English, published between January 1, 2000 and September 20, 2021. Participants had to be under 18 years old and with a diagnosis of LAR confirmed by nasal allergen provocation test (NAPT).

Results: Ten articles were identified. Despite the wide variability of protocols, prevalence rates ranged from 3.7 to $83.3 \%$ among children previously diagnosed as having nonallergic rhinitis, being markedly lower in Eastern countries (3.7-16.6\%) when compared to Western countries (22.3-83.3\%). To date, no relevant clinical characteristics capable of differentiating LAR patients from other childhood rhinitis phenotypes have been identified.

Conclusions: LAR is an allergic rhinitis phenotype also found in children. Population and regional differences and differences in NAPT protocols may explain the heterogeneity in LAR prevalence rates observed in different parts of the world. In addition to clarifying this large discrepancy, longitudinal studies are also needed to assess the clinical characteristics of the LAR phenotype in the pediatric age group, and its stability into adulthood must be confirmed. (๑) 2022 Codon Publications. Published by Codon Publications.
\end{abstract}

*Corresponding author: Fausto Yoshio Matsumoto, Rua dos Otonis, 725, 04025-002, São Paulo, Brazil. Email address: faustoym@gmail.com 


\section{Introduction}

Allergic rhinitis (AR) is one of the most prevalent chronic diseases in the world, affecting approximately $40 \%$ of people from different age groups. Between 5 and 25\% of children has rhinitis symptoms, ${ }^{1}$ which induce negative impacts on sleep, mood, social functioning, school performance, and high direct and indirect economic costs. ${ }^{2}$

Local allergic rhinitis (LAR) is a phenotype that is clinically very similar to classic AR, but it presents a nasal Th2 allergic inflammatory response, with no systemic allergic sensitization identified by the standard methods used in vivo (skin prick tests [SPTs]) or in vitro (quantification of specific serum IgE [slgE]). ${ }^{3}$ Its diagnosis is established by monitoring local responses during a nasal allergen provocation test (NAPT) ${ }^{4}$ to the relevant allergens in each region.

In adults, LAR is a well-defined and reported phenotype, predominantly affecting young, well-nourished, nonsmoking women with a family history of atopy. LAR symptoms are persistent and are often associated with allergic conjunctivitis and asthma. ${ }^{5}$ Approximately $36 \%$ of patients with LAR report its onset in childhood and persistence and worsening of rhinitis symptoms throughout life, considering it a stable rhinitis phenotype and not an early stage of classic AR. ${ }^{6}$ The identification of LAR and its consequent distinction from nonallergic rhinitis (NAR) have potential benefits for patients, such as the possibility of treating it with specific immunotherapy and implementing care to reduce environmental exposure to the identified allergens.

There is little information available about LAR in the pediatric age group, even data on prevalence and clinical characteristics. There is a clear need to learn more about this phenotype of rhinitis in the pediatric age group, to identify and institute early treatment in patients, which can provide a consequent improvement in quality of life and reduce burden of the disease.

\section{Objectives}

This systematic review aimed to identify and summarize information from original observational studies published on LAR in children and adolescents.

\section{Materials and Methods}

\section{Eligibility criteria}

For this review, a search for relevant articles was performed in PubMed and EMBASE databases on September 20, 2021. The search was limited to publications on humans, written in English, published between January 1, 2000 and September 20, 2021, using the following keywords for parameters: Local Allergic Rhinitis AND Children OR Adolescents; OR articles that contained Local Allergic Rhinitis in the title. We also performed an active manual search of the study references included in the review to identify additional studies with possible relevance (Figure 1).

A predefined list of inclusion and exclusion criteria (Table 1) was used to evaluate potentially relevant titles and summaries. After the search was completed, the articles were excluded from the analysis for multiple reasons: duplicate articles, study population with no differentiation between adults and children, full articles written in a language other than English, and conference summaries. Two researchers (FTM and TRTG) selected the articles independently, and if there was a difference of opinion, a third party (GFW) was brought in to break the tie.

Data were evaluated following PRISMA's (Preferred Reporting Items for Systematic reviews and Meta-Analyses) guidelines. ${ }^{7}$ Following the eligibility criteria, 396 titles and summaries were obtained, and one article $^{8}$ was found in an active search among the bibliographic references. After removing 13 duplicate articles, 384 titles and summaries were analyzed, and 336 were excluded based on the above exclusion and inclusion criteria. After thoroughly reading all 48 articles, 38 additional articles were excluded from the review. We tried unsuccessfully to contact four authors who presented data from children and adolescents but did not have a clear separation from adults. Therefore, they were excluded from the review.

\section{Results}

A total of 10 publications were selected, and a summary of their main findings is presented in Table 2.

Fuiano et al. ${ }^{8}$ evaluated the local production of nasal-specific IgE (nslgE) for Alternaria in children with clinical symptoms of rhinitis. A single-allergen NAPT (S-NAPT) was performed with Alternaria at concentrations of 0.2 , $0.5,0.8$, and $2.8 \mathrm{IR}$, and the test was only monitored subjectively (Nasal Symptoms Questionnaire).

Buntarickpornpan et al. ${ }^{9}$ performed an S-NAPT with Dermatophagoides pteronyssinus (DP) in children diagnosed with NAR (determined by negative systemic sensitization tests) between May 2014 and April 2015. A NAPT was performed with increasing concentrations of 200, 600, and $2000 \mathrm{AU} / \mathrm{mL}$, subjectively monitored by a Symptom Questionnaire (Lebel Questionnaire), Visual Analog Scale (VAS) and objectively monitored by Acoustic Rhinometry (AcRh) (positivity parameter: $>25 \%$ drop in the minimum cross-sectional area [MCA]) and peak nasal inspiratory flow (PNIF) (positivity parameter: $>40 \%$ drop). After evaluating the 54 patients, only 2 (3.7\%) were positive for NAPT with DP, with no change in levels of nasal tryptase or nslgE for DP $(<0.01 \mathrm{mcg} / \mathrm{L})$, before and after NAPT. ${ }^{9}$

Krajewska-Wojtys et al. ${ }^{10}$ performed the NAPT with multiple allergens (M-NAPT) using extracts with $5000 \mathrm{SBE} / \mathrm{mL}$ in 2-week intervals. The NAPT was monitored subjectively by VAS (positivity parameter: $\geq 30 \%$ increase of the total score) and objectively by AcRh (positivity parameter: $\geq 30 \%$ drop in nasal cavity volume between 2 and $6 \mathrm{~cm}$ [V2-6]). The authors found positive NAPT in 53/101 (52.5\%) patients, $17(16.8 \%)$ of them to Phleum pratense, $6(5.9 \%)$ to Artemisia, and $9(8.9 \%)$ to birch. Twenty-one patients (20.8\%) had positive NAPT to the three allergens. Unlike Buntarickpornpan et al.," they showed an increase in nslgE only for $P$. pratense after 6 hours of NAPT.

Duman et al. ${ }^{11}$ performed an M-NAPT with increasing concentrations of $0.1,1,10$, and $100 \mathrm{IR} / \mathrm{mL}$, and a 1 -week interval between the different allergens. The 


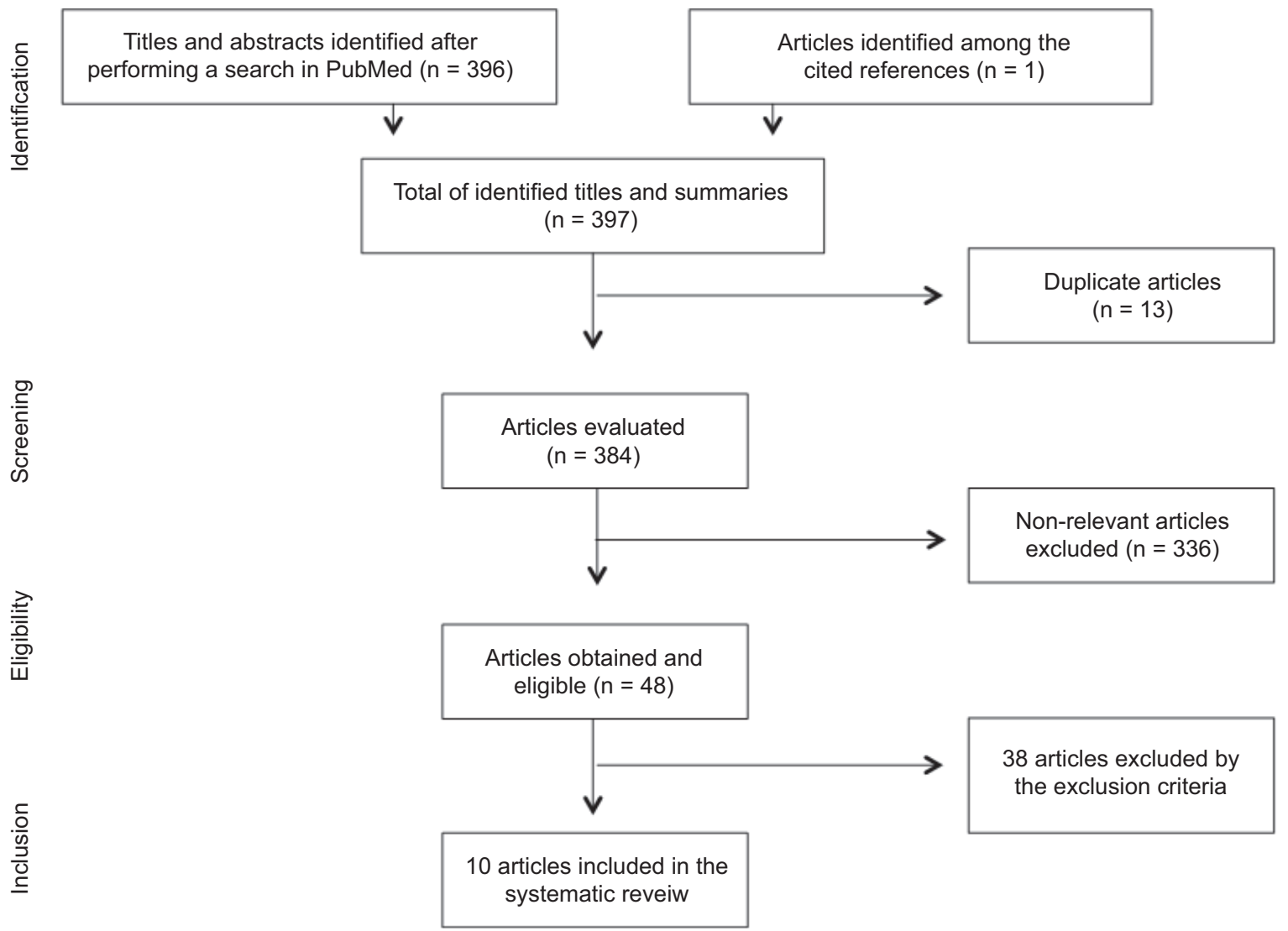

Figure 1 Flowchart of information obtained in the different phases of the systematic review.

Table 1 Inclusion and exclusion criteria for selecting eligible articles.

\begin{tabular}{|c|c|c|}
\hline Domain & Inclusion criteria & Exclusion criteria \\
\hline Participants & $\begin{array}{l}\text { Participants mandatorily under } 18 \text { years old; the } \\
\text { minimum age limited by the objective methods } \\
\text { used for diagnosing LAR, carrying out the NAPT. }\end{array}$ & $\begin{array}{l}\text { Studies with no age differentiation between adults } \\
\text { and children, presence of significant anatomical } \\
\text { defects of the upper respiratory tract (septum } \\
\text { deviation, adenoid hypertrophy, nasal polyposis). }\end{array}$ \\
\hline Intervention & $\begin{array}{l}\text { Mandatory NAPT to determine LAR, which may be } \\
\text { associated with dosage of other nasal markers, } \\
\text { such as cytokines or nasal-specific lgE (nslgE) }\end{array}$ & $\begin{array}{l}\text { No NAPT performed, regardless of other collected } \\
\text { markers. }\end{array}$ \\
\hline Outcome & $\begin{array}{l}\text { Quantification of patients identified as having LAR } \\
\text { exclusively in the pediatric age group }\end{array}$ & $\begin{array}{l}\text { Noninclusion of relevant outcome or } \\
\text { nonquantification of patients diagnosed with LAR }\end{array}$ \\
\hline Type of study & $\begin{array}{l}\text { Quantitative, observational, or intervention } \\
\text { studies }\end{array}$ & Review articles and qualitative studies \\
\hline $\begin{array}{l}\text { Type of } \\
\text { publication }\end{array}$ & Original peer-reviewed published articles & Conference summaries, case report \\
\hline
\end{tabular}

LAR: Local allergic rhinitis; NAPT: Nasal allergen provocation test; nslgE: Nasal-specific IgE

NAPTs were monitored subjectively by VAS and Total Nasal Symptom Score (TNSS) and objectively by Active Anterior Rhinomanometry (AAR) (positivity parameter: $>40 \%$ drop in nasal flow at 150 Pascals $(\mathrm{Pa})$ or $>20 \%$ drop in the nasal flow associated with $>2$ difference in TNSS). At the end of the evaluation, 7/28 (25\%) of the patients were diagnosed with LAR, and two children were positive to the grass mix, three to DP, and two to Dermatophagoides farinae (DF). There was no change in the quantification of eosinophils in nasal secretion.
Zicari et al. ${ }^{12}$ performed an M-NAPT with $100 \mathrm{AU}$ of each allergen (50 AU per nostril) and an interval longer than 2 days between provocations. The tests were subjectively monitored by a symptom questionnaire (NOSE score) ${ }^{13}$ and objectively by AAR (positivity parameter: $>50 \%$ drop in nasal flow at $150 \mathrm{~Pa}$ ). At the end of the assessment, $12 / 18(66.7 \%)$ were positive to at least one NAPT: six (33.3\%) were positive to house dust mite, five $(27.8 \%)$ were positive to grass pollen $\mathrm{mix}$, and one (5.6\%) was positive to both allergens. The authors also reported an increase 
Table 2 Summary of the main findings of the articles selected for the systematic review.

\begin{tabular}{|c|c|c|c|c|c|}
\hline $\begin{array}{l}\text { First Author, Study } \\
\text { location }\end{array}$ & $\begin{array}{l}\text { Year of } \\
\text { publication } \\
\text { (recruitment } \\
\text { period) }\end{array}$ & Age (Average age) & $\begin{array}{l}\text { Total number } \\
\text { of participants } \\
\text { (patients with } \\
\text { rhinitis with } \\
\text { no systemic } \\
\text { sensitization) }\end{array}$ & NAPT type & $\begin{array}{l}\text { Prevalence of } \\
\text { LAR (\%) }\end{array}$ \\
\hline Fuiano et al., ${ }^{8}$ Italy & 2012 & $\begin{array}{l}50-216 \text { months } \\
(137 \pm 43.2 \text { months })\end{array}$ & $56(36)$ & S-NAPT (Alternaria) & $30 / 36(83.3 \%)$ \\
\hline $\begin{array}{l}\text { Buntarickpornpan } \\
\text { et al., }{ }^{9} \text { Thailand }\end{array}$ & $\begin{array}{l}2016 \text { (May 2014- } \\
\text { April 2015) }\end{array}$ & $\begin{array}{l}8-18 \text { years } \\
(11.1 \pm 2.1 \text { years })\end{array}$ & $54(54)$ & S-NAPT (DP) & $2 / 54(3.7 \%)$ \\
\hline $\begin{array}{l}\text { Krajewska-Wojtys } \\
\text { et al., }{ }^{10} \text { Poland }\end{array}$ & 2016 & $\begin{array}{l}12-18 \text { years } \\
(15.4 \pm 3.8 \text { years })\end{array}$ & 101 (101) & $\begin{array}{l}\text { M-NAPT (Phleum } \\
\text { pratense, Artemisia, } \\
\text { and birch) }\end{array}$ & $53 / 101$ (52.5\%) \\
\hline Duman et al., ${ }^{11}$ Turkey & 2016 & $\begin{array}{l}5-16 \text { years } \\
(10.0 \pm 2.9 \text { years })\end{array}$ & $58(28)$ & $\begin{array}{l}\text { M-NAPT (grass pollen } \\
\text { mix, DP, and DF) }\end{array}$ & $7 / 28(25 \%)$ \\
\hline Zicari et al., ${ }^{12}$ Italy & 2016 & $\begin{array}{l}6-12 \text { years } \\
(8.33 \pm 1.71 \text { years })\end{array}$ & $18(18)$ & $\begin{array}{l}\text { M-NAPT (dust mite and } \\
\text { grass pollen) }\end{array}$ & $12 / 18(66.7 \%)$ \\
\hline Ha et al., ${ }^{14}$ Korea & $\begin{array}{l}2017 \text { (May 2011- } \\
\text { Jun 2012) }\end{array}$ & $\begin{array}{l}1-18 \text { years } \\
(5.9 \pm 3.3 \text { years })\end{array}$ & $145(64)$ & S-NAPT (Der p1) & $5 / 64(7.8 \%)$ \\
\hline Tao et al., ${ }^{16}$ China & $\begin{array}{l}2018 \text { (Mar 2016- } \\
\text { Mar 2017) }\end{array}$ & $<14$ years & $40(6)$ & $\begin{array}{l}\text { M-NAPT (weed pollen } \\
\text { mix, house dust mite } \\
\text { mix, and mold mix) }\end{array}$ & $1 / 6(16.6 \%)$ \\
\hline Bozek et al., ${ }^{17}$ Poland & 2019 & $5-18$ years & $293(152)$ & $\begin{array}{l}\text { M-NAPT (DP, } P \text {. } \\
\text { pratense, Artemisia, } \\
\text { birch and cat) }\end{array}$ & $34 / 152(22.3 \%)$ \\
\hline $\begin{array}{l}\text { Tsilochristou et al., }{ }^{18} \\
\text { Greece }\end{array}$ & $\begin{array}{l}2019 \text { (Oct 2016- } \\
\text { Sep 2017) }\end{array}$ & $6-18$ years & $86(24)$ & $\begin{array}{l}\text { M-NAPT ( } P \text {. pratense, } \\
\text { Olea europaea, } \\
\text { Alternaria Alternata, } \\
\text { and DP) }\end{array}$ & $7 / 24$ (29.2\%) \\
\hline Prieto et al., ${ }^{20}$ Spain & $\begin{array}{l}2021 \text { (Jan 17- } \\
\text { Dec 19) }\end{array}$ & $\begin{array}{l}5-18 \text { years } \\
(15.1 \pm 2.2 \text { years })\end{array}$ & $173(74)$ & $\begin{array}{l}\text { M-NAPT (grass-mix } \\
\text { pollen, O. europaea, } A \text {. } \\
\text { alternata, } P \text {. judaica, } \\
\text { DP) }\end{array}$ & $43 / 74(58.11 \%)$ \\
\hline
\end{tabular}

DF: Dermatophagoides farinae; DP: Dermatophagoides pteronyssinus; M-NAPT: Nasal allergen provocation test with multiple allergens; S-NAPT: Single-allergen nasal allergen provocation test

in interleukin-5, Thymic stromal lymphopoietin (TSLP; 33\% of the children with positive NAPT), and nslgE for allergens tested after the NAPT, but it must be noted that the author used $0.1 \mathrm{kU} / \mathrm{L}$ as the cutoff value to consider the nslgE positive. Otherwise, the author justifies that this difference could be explained by considering that the samples were $50 \%$ more concentrated than the original volume.

$\mathrm{Ha}$ et al. ${ }^{14}$ performed S-NAPTs with 0.4 and $4 \mu \mathrm{g} / \mathrm{mL}$ of freshly reconstituted freeze-dried DP between May 2011 and June 2012, monitored only subjectively by VAS and Total Symptom Score. They used the within-subject standard deviation (SDW) as a positivity parameter, calculated by dividing the difference of the symptom scores between the initial value and the value after saline challenge by the square root of $2 .{ }^{15}$ An SD index value >2 SDs was categorized as positive.

Tao et al. ${ }^{16}$ performed M-NAPTs between March 2016 and March 2017 using the following concentrations: house dust mite mix, $22 \mathrm{mg} / \mathrm{mL}$; weed pollen mix, $50 \mathrm{mg} / \mathrm{mL}$; and mold mix, $40 \mathrm{mg} / \mathrm{mL}$, with unspecified intervals between NAPTs. Nasal provocations were monitored subjectively by VAS and objectively by AAR, using as a positive parameter: an increase of $>30 \%$ in the total VAS, accompanied with an increase of $>100 \%$ in total airway resistance at $150 \mathrm{~Pa}$, or an increase of $>15 \%$ in the eosinophil ratio in the nasal secretion smear. The study included adults and children, but only patients under 14 years old $(n=40)$ were analyzed for this systematic review.

Bozek et al. ${ }^{17}$ performed M-NAPTs with $5000 \mathrm{SBE} / \mathrm{mL}$ extracts in 2-week intervals. The NAPT was monitored subjectively by VAS (positivity parameter: $\geq 30 \%$ increase) and objectively by AcRh (positivity parameter: $\geq 30 \%$ drop in V2-6). The study included adults and children, but only patients under 18 years old with positive NAPTs $(n=293)$ were analyzed for this systematic review. Despite the NAPTs being divided by age group, the clinical characteristics 
were not separated in the same way, and it is not possible to extract data to clinically categorize children with LAR. In adults, unlike Rondon et al., ${ }^{5}$ they noted that the typical characteristics of patients with LAR in this group were as follows: older men with more perennial types of symptoms who are monosensitized, mainly to DP.

Tsilochristou et al. ${ }^{18}$ performed M-NAPTs between October 2016 and September 2017, with doses of $P$. pratense, Olea europaea, Alternaria alternata (all $30 \mathrm{HEP}$ / $\mathrm{mL})$, and DP (100 HEP/mL) on the same day per the protocol developed by Rondon et al., ${ }^{19}$ with a preestablished order depending on the length of symptoms reported. Children were given another M-NAPT no earlier than 7 days from the positive M-NAPT, and the confirmative single NAPT took place after at least 3 weeks. The M-NAPT was monitored subjectively by VAS (positivity parameter: $\geq 30 \%$ increase) and objectively by AcRh (positivity parameter: $\geq 30 \%$ drop in V2-5).

Prieto et al. ${ }^{20}$ performed M-NAPTs with grass-mix pollen, O. europaea, A. alternata, Parietaria judaica (all $30 \mathrm{HEP} / \mathrm{mL})$, and DP (100 HEP/mL). Individuals exposed to pets were also provoked with cat and dog allergens (both $30 \mathrm{HEP} / \mathrm{mL})$. Four increasing concentrations $(1 / 100,1 / 10$, $1 / 2$, and undiluted) were used for each allergen. The NAPT was monitored subjectively by VAS (positivity parameter: $\geq 30 \%$ increase) and objectively by AcRh, using as a parameter for positivity: a drop $\geq 30 \%$ in V2-6 (patients $\geq 160 \mathrm{~cm}$ tall) or V2-4 (patients $<160 \mathrm{~cm}$ tall). The authors found that DP was the leading elicitor of LAR.

Only four authors assessed the clinical characteristics of children diagnosed with LAR (Table 3). Duman et al. ${ }^{11}$ found that patients with LAR had disease durations of $3.9 \pm$

Table 3 Leading clinical characteristics described associated with local allergic rhinitis in the articles selected for systematic review.

\begin{tabular}{ll}
\hline Author & Clinical characteristics \\
\hline Duman et al. ${ }^{11}$ & Rhinitis duration $3.9 \pm 2.0$ years \\
& $71.4 \%$ male gender \\
& $28.6 \%$ asthma \\
& $57.1 \%$ Moderate-to-severe rhinitis \\
& $80 \%$ male gender \\
Ha et al. ${ }^{13}$ & $20 \%$ asthma \\
& $57.1 \%$ male gender \\
Tsilochristou et al. ${ }^{16}$ & $57.1 \%$ family atopy \\
& $71.4 \%$ atopic dermatitis \\
& $42.9 \%$ asthma \\
& $32.6 \%$ male gender \\
& Family atopy \\
& Allergic conjunctivitis \\
& Moderate-to-severe rhinitis \\
& Itching \\
& Sneezing \\
& Symptoms triggered by house \\
& dust and vegetation and a trend \\
& toward clinical worsening over \\
& time.
\end{tabular}

2.0 years: $5 / 7$ patients $(71.4 \%)$ were male, $2 / 7(28.6 \%)$ had asthma, and $4 / 7$ (57.1\%) had moderate-to-severe persistent rhinitis, but none of these characteristics were significantly different from those manifested by the group diagnosed with NAR. Ha et al. ${ }^{14}$ observed that among patients with LAR, 4/5 patients (80\%) were male, $1 / 5(20 \%)$ had asthma, and there was also no significant difference between the LAR, AR, and NAR groups. Tsilochristou et al. ${ }^{18}$ also did not observe differences regarding gender (57.1\% male), family atopy (57.1\%), place of residence (urban or rural), or comorbidities such as atopic dermatitis (71.4\%) and asthma $(42.9 \%)$. Prieto et al., ${ }^{20}$ unlike the other authors, found 29/43 female patients (67.4\%) and identified some characteristics with significant differences between the LAR and NAR groups. In children with LAR, they observed higher frequency of family history of atopy (OR: $4.13 ; 95 \% \mathrm{Cl}$ : 1.53-11.12), greater coexistence with allergic conjunctivitis (OR: 5.24; 95\% Cl: 1.85-14.84), greater presence of moderate-to-severe rhinitis (OR: 7.96; 95\%Cl: 2.75-23.04), nasal itching (OR: 4.40; 95\% Cl: 1.60-12.01), sneezing (OR: 4.01; 95\% Cl: 1.47-10.99), symptoms triggered by house dust and vegetation, and a trend toward clinical worsening over time. On the other hand, milder symptoms elicited by irritant smells and nasal obstruction were more common among those with NAR. However, these characteristics did not differentiate LAR patients from AR patients.

\section{Discussion}

We observed a vast variation in the LAR diagnosis rates (3.7-83.3\%) in children and adolescents previously classified as having NAR. These are markedly lower in Eastern countries (3.7-16.6\%) when compared to Western countries (22.3-83.3\%). Differences in populations and regions, the relevance of seasonal allergens, and the pattern of sensitization and differences in the local prevalence of allergic sensitization may justify the differences obtained between studies on children.

Despite LAR being a well-established phenotype of AR in adulthood, there are few studies that assess its prevalence, specifically in the pediatric age group. This lack of data is partly due to the difficulty in diagnosing children (technical difficulty in performing NAPTs in the pediatric age group, lack of technical knowledge, availability of equipment or resources, and time consumption) and partly also due to the lack of clinical interest in performing the complete differentiation between this rhinitis phenotype and NAR, which has a lower prevalence in children. Furthermore, everyday drug treatment is often carried out empirically regardless of the rhinitis phenotype. However, in adults, the identification of LAR and its consequent distinction from NAR have potential benefits for patients, such as the possibility of treating it with specific immunotherapy and implementing care to reduce environmental exposure to the identified allergens. Clinical trials with immunotherapy for children with LAR have not yet been performed. Once they emerge, we will be able to assess whether children will also benefit from this treatment.

The allergen choice to the NAPT from every publication in this study was specifically based on the etiological relevance of $A R$ at the study site, and when seasonal allergens 
were used, NAPTs were performed at times of the year not known for pollination, decreasing the chance of interference with nasal patency. Thus, choosing to perform an S-NAPT or M-NAPT was closely interlinked with the presence of seasonal and/or perennial AR in each region.

Although the choice of allergens was justified by local characteristics, the NAPTs showed a clear lack of standardization in many aspects, making it difficult to compare authors from different locations in the world. Among the factors evaluated were as follows: concentrations of allergen extracts presented differently $(\mathrm{AU} / \mathrm{mL}, \mathrm{IR}, \mathrm{SBE} /$ $\mathrm{mL}, \mathrm{HEP} / \mathrm{mL}$ ), variable instillation protocols (dosage, concentrations, and intervals between M-NAPTs), and standardization was lacking in the forms of subjective and objective monitoring. Objective monitoring is essential in performing and interpreting NAPTs and can be performed in many ways. For example, when AcRh is chosen, factors such as which parameter should be used (MCA or nasal volume) and which cutoff points should be used to consider a positive NAPT must be defined. The cutoff points defined to consider NAPT positivity also varied when the PNIF or $A A R$ was used. Even after the EAACI position paper on the standardization of nasal allergen challenges ${ }^{21}$ (Table 4) was published in 2018, we verified that the articles maintain heterogeneity in presenting results.

Two articles (Fuiano et al. ${ }^{8}$ and $\mathrm{Ha}$ et al..$^{14}$ ) only monitored the NAPT subjectively, using questionnaires. There was no objective monitoring, as currently proposed by the EAACI position paper on the standardization of nasal allergen challenges. ${ }^{21}$ This fact justifies the inclusion of younger children in these studies because the objective NAPT monitoring methods are usually technically difficult to be employed in preschool children (AcRh, PNIF, and AAR). Fuiano et al. ${ }^{8}$ are also not clear on whether the NAPT protocol with Alternaria was previously validated or performed on control patients or patients without AR, ensuring that the extracts used do not cause irritation.

The relevance of cytokines in nasal secretion is another point that should be clarified in LAR in children and adolescents. Th2 nasal cytokine measurements were performed among the selected studies, such as IL-5 (12),
TSLP, ${ }^{12}$ tryptase, ${ }^{9,16}$ nslgE, ${ }^{8-10,12,16,17}$ and nasal eosinophils, ${ }^{11,12,16}$ demonstrating heterogeneous results in patients with LAR. Although these tests are less invasive, the NAPT remains the gold standard for diagnosing LAR.

Particular attention should be paid to nslgE values. Rondon et al. ${ }^{22}$ reported that slgE levels in nasal lavage have high specificity but low sensitivity (up to 40\%), possibly associated with two factors. The first is related to the small amounts of nslgE found in patients with LAR, and it is likely that this occurs due to local extravasation through the nasal mucosa once the local synthesis of IgE has not been demonstrated. ${ }^{23}$ The second, by the possible dilution effect related to the nasal lavage method of Naclerio et al., ${ }^{24}$ used to detect nslgE in some studies. In this systematic review, some authors performed the nasal lavage method of Naclerio et al. ${ }^{24}$ (Buntarickpornpan e tal., ${ }^{9}$ Krajewska et al., ${ }^{10}$ Zicari et al. ${ }^{12}$ ), others used a sinus pack placed in the nasal common meatus to absorb nasal secretions (Tao et al. $^{16}$ ) or the detection of IgE antibody in situ on nasal mucosa method used by Marcucci and Sensi ${ }^{25}$ (Fuiano et al.).

The LAR phenotype in adults appears to be associated with young, well-nourished, nonsmoking women with a family history of atopy, persistent perennial rhinitis, and frequently associated with conjunctivitis and asthma. ${ }^{5}$ The clinical characteristics in the pediatric age group, although described in some studies, are still unclear, and it is not possible to clinically differentiate them from other rhinitis phenotypes (AR and NAR).

\section{Summary of evidence}

The 10 articles included in this systematic review had a large variation in LAR diagnosis rates (3.7-83.3\%) in children and adolescents that were previously categorized as affected by NAR, with markedly lower rates in Eastern countries (3.7-16.6\%) when compared Western countries (22.3-83.3\%). To date, no relevant clinical characteristics capable of differentiating LAR patients from other childhood rhinitis phenotypes have been identified.

Table 4 Recommendations of parameters to be used to consider a specific nasal provocation test as positive.

\begin{tabular}{|c|c|c|}
\hline Method & Clearly positive & Moderately positive \\
\hline \multicolumn{3}{|l|}{ Subjective measures } \\
\hline Visual Analog Scale (VAS) & Symptoms $\geq 55 \mathrm{~mm}$ & Symptoms $\geq 23 \mathrm{~mm}$ \\
\hline Lebel score & Increase $\geq 5$ points & Increase $\geq 3$ points \\
\hline Linder Score & Increase $\geq 5$ points & Increase $\geq 3$ points \\
\hline Total Nasal Symptom Score (TNSS) & Increase $\geq 5$ points & Increase $\geq 3$ points \\
\hline \multicolumn{3}{|l|}{ Objective measures } \\
\hline Peak nasal inspiratory flow (PNIF) & Flow decrease of $\geq 40 \%$ & Flow decrease of $\geq 20 \%$ \\
\hline Active anterior rhinomanometry (AAR) & Flow decrease of $\geq 40 \%$ at $150 \mathrm{~Pa}$ & Flow decrease of $\geq 20 \%$ at $150 \mathrm{~Pa}$ \\
\hline Acoustic rhinometry (AcRh) & MCA-2 decrease of $\geq \_40 \%$ & Decrease in sum of $2-6 \mathrm{~cm}^{2} \geq 27 \%$ bilaterally \\
\hline 4-phase rhinomanometry (4PR) & $\begin{array}{l}\geq 40 \% \text { increase in logarithmic }(\mathrm{lg}) \\
\text { effective resistance }\end{array}$ & $\begin{array}{l}\geq 20 \% \text { increase in logarithmic (lg) effective } \\
\text { resistance }\end{array}$ \\
\hline
\end{tabular}

Adapted from the Augé et al. EAACl position paper on the standardization of nasal allergen challenges. ${ }^{21}$ 


\section{Limitations}

There are several limitations to our findings. First, the small number of articles published exclusively on the pediatric age group and the small number of participants in each article demonstrate the difficulty of measuring the prevalence and characteristics of LAR in children and adolescents around the world. Second, the lack of NAPT standardization and LAR diagnosis make comparisons between studies difficult, even when the allergens used are similar. Third, having only cross-sectional studies on children does not allow us to evaluate the stability of LAR as a phenotype until adulthood. This data is significant once it is known that the prevalence of positive SPT results and rhinitis increases with age $^{26}$ and that $36 \%$ of adults with LAR report the onset of rhinitis during childhood. ${ }^{27}$

\section{Conclusions}

As observed in adults, we can state that LAR is also a phenotype described and found in the pediatric age group. Additional studies from different parts of the world are necessary to clarify LAR prevalence, clinical characteristics, and stability in children. Furthermore, future publications may investigate the large discrepancy between the rates obtained in Eastern and Western countries and prove the efficiency of immunotherapy in the childhood rhinitis phenotype. Standardizing NAPTs is essential to allow better comparisons among studies. Several aspects of the NAPTs should be standardized, such as defining the best parameters to be used in NAPTs objective monitoring methods on children, and appropriate concentrations to be used and intervals in cases of M-NAPTs. Furthermore, standardizing the technique for measuring nslgE and other nasal cytokines, and using the basophil activation test (BAT), could make data collection more manageable, more consistent, and clear, favorable to carrying out more studies on this age group. Longitudinal studies are needed to assess the LAR phenotype stability during childhood through adulthood.

\section{Funding}

Coordenação de Aperfeiçoamento de Pessoal de Nível Superior (CAPES, Brazil).

Fundação de apoio à Pesquisa do Estado de São Paulo (FAPESP): Grant 2017/03075-2.

\section{References}

1. Bousquet J, Khaltaev N, Cruz AA, Denburg J, Fokkens WJ, Togias A, et al. Allergic rhinitis and its impact on asthma (ARIA) 2008 update (in collaboration with the World Health Organization, GA2LEN and AllerGen). Allergy Eur J Allergy Clin Immunol. 2008;63(Suppl 86):8-160. https://doi. org/10.1111/j.1398-9995.2007.01620.x

2. Meltzer EO, Bukstein DA. The economic impact of allergic rhinitis and current guidelines for treatment. Ann Allergy Asthma Immunol. 2011;106(2 SUPPL.):12-6. https://doi.org/10.1016/j. anai.2010.10.014.
3. Campo P, Rondón C, Gould HJ, Barrionuevo E, Gevaert P, Blanca M. Local IgE in non-allergic rhinitis. Clin Exp Allergy. 2015;45(5):872-81. https://doi.org/10.1111/cea.12476

4. Rondón C, Fernández J, López S, Campo P, Doña I, Torres MJ, et al. Nasal inflammatory mediators and specific IgE production after nasal challenge with grass pollen in local allergic rhinitis. J Allergy Clin Immunol. 2009;124(5):1005-12. https:// doi.org/10.1016/j.jaci.2009.07.018

5. Rondón C, Campo P, Zambonino MA, Blanca-Lopez N, Torres MJ, Melendez L, et al. Follow-up study in local allergic rhinitis shows a consistent entity not evolving to systemic allergic rhinitis. J Allergy Clin Immunol. 2014;133(4):1026-31. https://doi.org/10.1016/j.jaci.2013.10.034

6. Rondón C, Campo P, Eguiluz-Gracia I, Plaza C, Bogas G, Galindo $\mathrm{P}$, et al. Local allergic rhinitis is an independent rhinitis phenotype: The results of a 10-year follow-up study. Allergy Eur J Allergy Clin Immunol. 2018;73(2):470-8. https:// doi.org/10.1111/all.13272

7. Moher D, Liberati A, Tetzlaff J, Altman DG, Altman D, Antes G, et al. Preferred reporting items for systematic reviews and meta-analyses: The PRISMA statement. PLoS Med. 2009;6(7). https://doi.org/10.1371/journal.pmed.1000097

8. Fuiano N, Fusilli S, Incorvaia C. A role for measurement of nasal IgE antibodies in diagnosis of Alternaria-induced rhinitis in children. Allergol Immunopathol (Madr) 2012;40(2):71-4. https://doi.org/10.1016/j.aller.2011.03.010

9. Buntarickpornpan P, Veskitkul J, Pacharn P, Visitsunthorn N, Vichyanond $\mathrm{P}$, Tantilipikorn $\mathrm{P}$, et al. The proportion of local allergic rhinitis to Dermatophagoides pteronyssinus in children. Pediatr Allergy Immunol. 2016;27(6):574-9. https://doi. org/10.1111/pai.12606

10. Krajewska-Wojtys A, Jarzab J, Gawlik R, Bozek A. Local allergic rhinitis to pollens is underdiagnosed in young patients. Am J Rhinol Allergy. 2016;30(6):e198-201. https://doi.org/10.2500/ ajra.2016.30.4369.

11. Duman H, Bostanci I, Ozmen S, Dogru M. The relevance of nasal provocation testing in children with nonallergic rhinitis. Int Arch Allergy Immunol. 2016;170(2):115-21. https://doi. org/10.1159/000447635

12. Zicari AM, Occasi F, Di Fraia M, Mainiero F, Porzia A, Galandrini R, et al. Local allergic rhinitis in children: Novel diagnostic features and potential biomarkers. Am J Rhinol Allergy. 2016;30(5):329-34. https://doi.org/10.2500/ ajra.2016.30.4352

13. Zicari AM, Occasi F, Giulia M, Indinnimeo L, De Castro G, Tancredi G, et al. Intranasal budesonide in children affected by persistent allergic rhinitis and its effect on nasal patency and Nasal Obstruction Symptom Evaluation (NOSE) score. Curr Med Res Opin. 2015;31(3):391-6. https://doi.org/10.1185/03007 995.2015.1009532

14. Ha EK, Na MS, Lee S, Baek H, Lee SJ, Sheen YH, et al. Prevalence and clinical characteristics of local allergic rhinitis in children sensitized to house dust mites. Int Arch Allergy Immunol. 2017;174(3-4):183-9. https://doi. org/10.1159/000481091

15. Loland L, Buchvald FF, Halkjær LB, Anhøj J, Hall GL, Persson T, et al. Sensitivity of bronchial responsiveness measurements in young infants. Chest. 2006;129(3):669-75. https://doi. org/10.1378/chest.129.3.669

16. Tao XY, Ng CL, Chen D, Lin Z Bin, Wu SL, Liang MJ, et al. Clinical characteristics and allergen sensitization patterns of patients with local allergic rhinitis in Southern China. Int Arch Allergy Immunol. 2018;175(1-2):107-13. https://doi. org/10.1159/000485896

17. Bozek A, Scierski W, Ignasiak B, Jarzab J, Misiolek M. The prevalence and characteristics of local allergic rhinitis in Poland. Rhinology. 2019;57(3):213-8. https://doi.org/10.4193/ Rhin18.137 
18. Tsilochristou O, Kyriakakou M, Manolaraki I, Lakoumentas J, Tiligada E, Maragkoudakis $P$, et al. Detection of local allergic rhinitis in children with chronic, difficult-to-treat, non-allergic rhinitis using multiple nasal provocation tests. Pediatr Allergy Immunol. 2019;30(3):296-304. https://doi.org/10.1111/ pai.13021

19. Rondón C, Campo P, Herrera R, Blanca-Lopez N, Melendez L, Canto $\mathrm{G}$, et al. Nasal allergen provocation test with multiple aeroallergens detects polysensitization in local allergic rhinitis. J Allergy Clin Immunol. 2011;128(6):1192-7. https://doi. org/10.1016/j.jaci.2011.06.012

20. Prieto A, Rondón C, Eguiluz-Gracia I, Muñoz C, TesteraMontes A, Bogas G, et al. Systematic evaluation of allergic phenotypes of rhinitis in children and adolescents. Pediatr Allergy Immunol. 2021;32(5):953-62. https://doi.org/10.1111/pai.13474

21. Augé J, Vent J, Agache I, Airaksinen L, Campo Mozo P, Chaker A, et al. EAACI Position paper on the standardization of nasal allergen challenges. Allergy Eur J Allergy Clin Immunol. 2018;73(8):1597-608. https://doi.org/10.1111/all.13416

22. Rondón C, Campo P, Togias A, Fokkens WJ, Durham SR, Powe DG, et al. Local allergic rhinitis: Concept, pathophysiology, and management. J Allergy Clin Immunol. 2012;129(6):1460-7. https://doi.org/10.1016/j.jaci.2012.02.032

23. Eguiluz-Gracia I, Layhadi JA, Rondon C, Shamji MH. Mucosal IgE immune responses in respiratory diseases. Curr Opin Pharmacol. 2019;46:100-7. https://doi.org/10.1016/j. coph.2019.05.009

24. Naclerio R, Creticos PS, Norman PS, Lichtenstein LM. Mediator release after nasal airway challenge with allergen. Am Rev Respir Dis. 1986;5:1102. https://doi.org/10.1164/ arrd.1986.134.5.1102

25. Marcucci F, Sensi L. A new method for IgE detection in nasal mucosa. Clin Exp Allergy. 1989;2(19):157-62. https://doi. org/10.1111/j.1365-2222.1989.tb02358.x

26. Kulig M, Klettke U, Wahn V, Forster J, Bauer CP, Wahn U. Development of seasonal allergic rhinitis during the first 7 years of life. J Allergy Clin Immunol. 2000;106(5):832-9. https://doi.org/10.1067/mai.2000.110098

27. Rondón C, Campo P, Galindo L, Blanca-Lõpez N, Cassinello MS, Rodriguez-Bada JL, et al. Prevalence and clinical relevance of local allergic rhinitis. Allergy Eur J Allergy Clin Immunol. 2012;67(10):1282-8. https://doi.org/10.1111/all.12002 